\title{
A Tricatecholic Receptor for Carbohydrate Recognition: Synthesis and Binding Studies
}

\author{
Martina Cacciarini, ${ }^{\dagger, \S}$ Elisa Cordiano, ${ }^{\dagger}$ Cristina Nativi, ${ }^{\dagger, \S}$ and Stefano Roelens ${ }^{*, \neq, \S}$ \\ Dipartimento di Chimica Organica and Laboratorio di Progettazione Sintesi e Studio di Eterocicli \\ Biologicamente Attivi (HeteroBioLab), Università di Firenze, and Istituto di Metodologie Chimiche \\ (IMC), Consiglio Nazionale delle Ricerche (CNR), Polo Scientifico e Tecnologico,
}

I-50019 Sesto Fiorentino, Firenze, Italy

stefano.roelens@unifi.it

\footnotetext{
${ }^{\dagger}$ Dipartimento di Chimica Organica.

${ }^{\S}$ HeteroBioLab.

${ }^{\ddagger}$ CNR - IMC.
}

\section{SUPPORTING INFORMATION}

General

Materials

Titrations and Data Analysis

Titrations Plots - Figure S1

References and Notes

NMR Spectral Data p. S2

p. S2

p. S2

p. S3

p. $\mathrm{S} 4$

p. S5 


\section{Experimental Section}

General. ${ }^{1} \mathrm{H}$ NMR spectra were recorded at 200 or $400 \mathrm{MHz}$ and ${ }^{13} \mathrm{C}$ NMR spectra at $50 \mathrm{MHz}$. Chemical shifts are reported in part per million $(\delta)$ relative to TMS, using the solvent line as secondary internal reference [residual $\mathrm{CHCl}_{3}\left(\delta\right.$ 7.26) for ${ }^{1} \mathrm{H}$ NMR spectra and $\mathrm{CDCl}_{3}(\delta 77.0)$ for ${ }^{13} \mathrm{C} \mathrm{NMR}$ spectra]. Mass spectra were recorded on quadrupole mass spectrometer by direct introduction. Melting points are uncorrected.

Materials. Reagents were purchased from commercial suppliers and used without further purification. $\alpha$ Glc, $\beta$ Glc and $\beta$ Gal were commercially available; the other octyl glycosides were known compounds $^{\mathrm{S} 1}$ and were prepared according to a literature method. ${ }^{\mathrm{S} 2}$ 1,3,5-Tris-(bromomethyl)-2,4,6triethylbenzene $\mathbf{4}$ has been previously described. ${ }^{4}$ Where necessary, spectral assignments were performed through 2D-NMR spectra.

2-Methoxy-1,3-benzodioxol-4-ol (5): ${ }^{\mathrm{S} 3}$ Pyrogallol 3 (1.00 g, $\left.7.97 \mathrm{mmol}\right)$ and trimethylorthoformate $(0.9 \mathrm{~mL}, 0.873 \mathrm{~g}, 8.23 \mathrm{mmol})$ in toluene $(20 \mathrm{~mL})$ were heated under reflux for $2 \mathrm{~h}$. The reaction mixture was cooled to $0{ }^{\circ} \mathrm{C}$, filtered to remove the unreacted pyrogallol and concentrated under vacuum to give 5 (1.81 g, $10.8 \mathrm{mmol}, 50 \%)$ as a yellowish oil which was used without further purification. ${ }^{1} \mathrm{H}$ NMR $\left(\mathrm{CDCl}_{3}, 200 \mathrm{MHz}\right) \delta 6.86$ (s, 1H), 6.75-6.71 (m, 1H), 6.53-6.49 (m, 2H), $5.34(\mathrm{~s}, 1 \mathrm{H}), 3.42(\mathrm{~s}, 3 \mathrm{H}) ;{ }^{13} \mathrm{C}$ NMR $\left(\mathrm{CDCl}_{3}, 50 \mathrm{MHz}\right) \delta 147.1,138.9,132.8,122.1,119.4,110.9,101.3,50.0$.

Titrations and Data Analysis. Titrations and dilution experiments were performed in $\mathrm{CDCl}_{3}$ stored over activated molecular sieves at $298 \mathrm{~K}$ by ${ }^{1} \mathrm{H}$ NMR Spectrometry at $400 \mathrm{MHz}$ in $5 \mathrm{~mm}$ NMR tubes, using Hamilton microsyringes and following a previously described technique. ${ }^{4}$ To avoid interference of traces of acid in solution, $\mathrm{CDCl}_{3}$ was additionally treated by eluting through a short column of alumina right before use. Mathematical analysis of data and graphic presentation of results was done through nonlinear regression analysis using the HypNMR $2006{ }^{\text {S4 }}$ computer program from Protonic Software, available at http://www.hyperquad.co.uk. The program performs simultaneous fit of multiple signals to models involving multiple equilibria, giving binding constants and chemical shifts of individual species. $B C_{50}$ Calculator, the utility program for computing $B C_{50}$ and $B C_{50}^{0}, 8$ is available for free at the corresponding author’s e-mail address. 

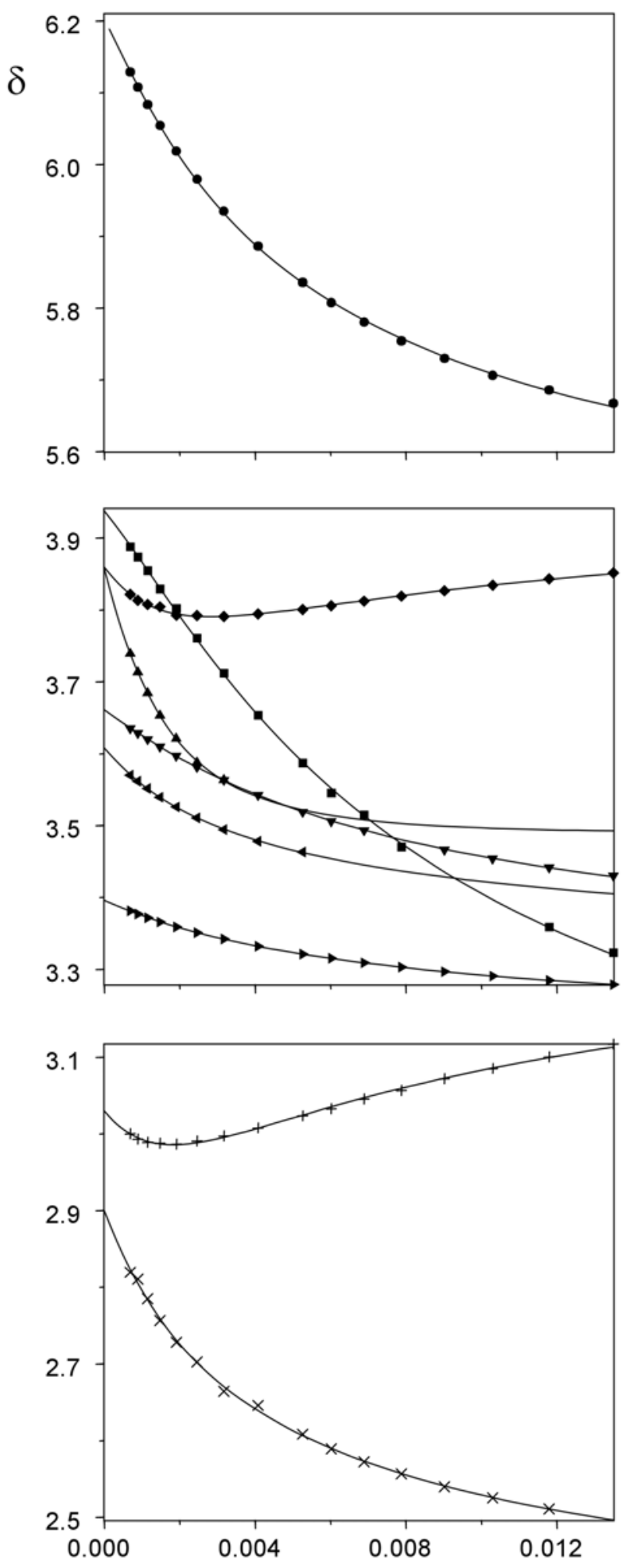

Total Receptor Concentration / mol L-1

Figure S1. Plot of complexation induced shifts vs receptor's total concentration in the titration of $\alpha$ Man $1.0 \mathrm{mM}$ with 7 in $\mathrm{CDCl}_{3}$ at $400 \mathrm{MHz}$ and $T=298 \mathrm{~K}$. Bottom: mannose $\mathrm{OH}$ signals $(\times \mathbf{O H}-2 ;+\mathrm{OH}-4)$;

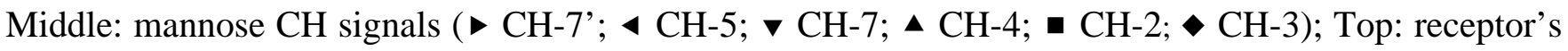
catechol OH-A signal. Symbols are experimental data points; solid lines are best fit curves obtained through nonlinear regression by simultaneous fit of all data. 


\section{References and Notes}

(S1) Mizutani, T.; Kurahashi, T.; Murakami, T.; Matsumi, N.; Ogoshi, H. J. Am. Chem. Soc. 1997, 119, 8991-9001.

(S2) Adasch, V.; Hoffmann, B.; Milius, W.; Platz, G.; Voss, G. Carbohydr. Res. 1998, 314, 177-187.

(S3) Gates, Peter S. Ger. Patent DE 2618393 (1976), (23 pp.); CAN 86:55415, AN 1977:55415.

(S4) Frassineti, C.; Ghelli, S.; Gans, P.; Sabatini, A.; Moruzzi, M. S.; Vacca, A. Anal. Biochem. 1995, 231, 374-382. 


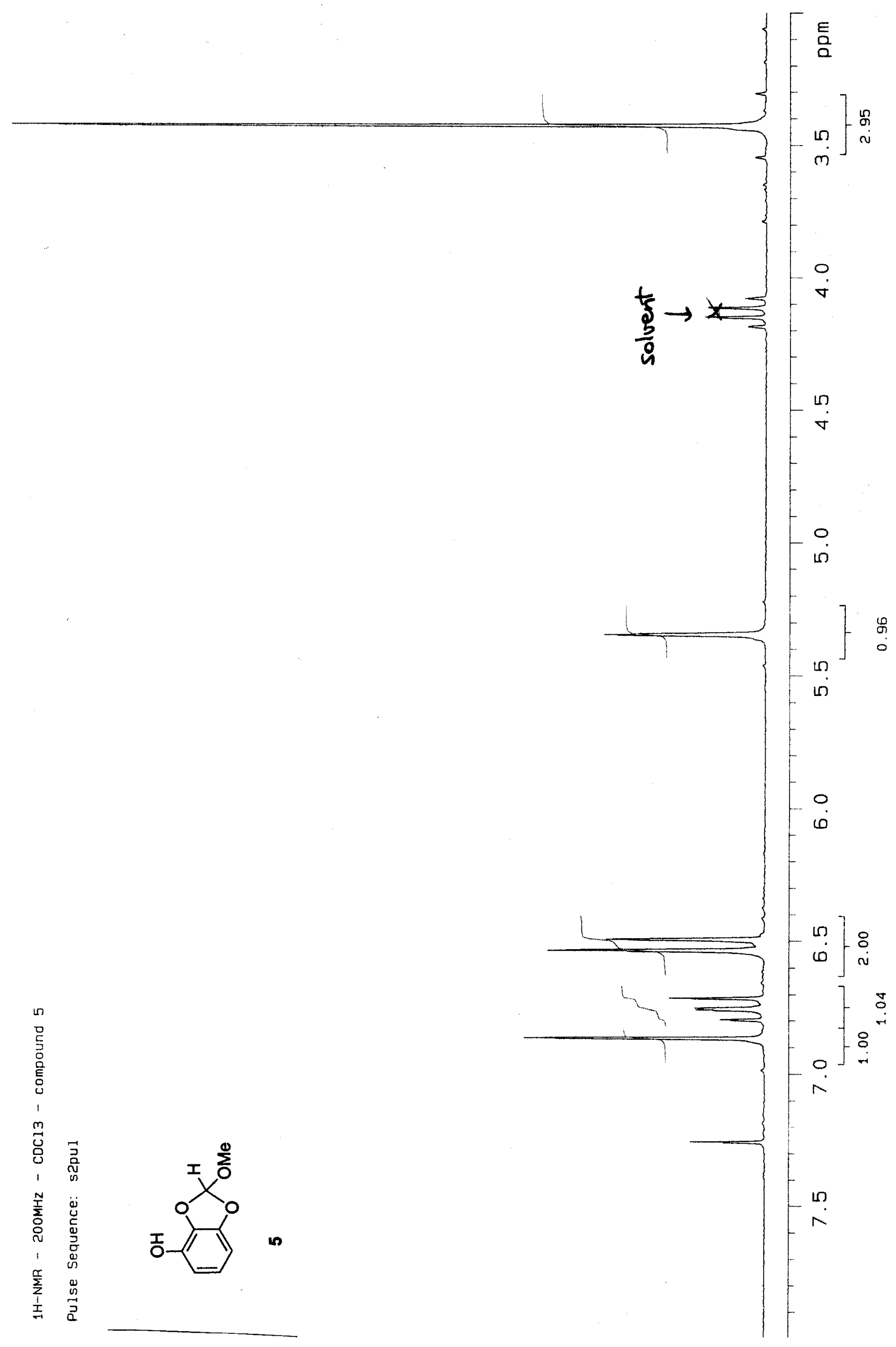




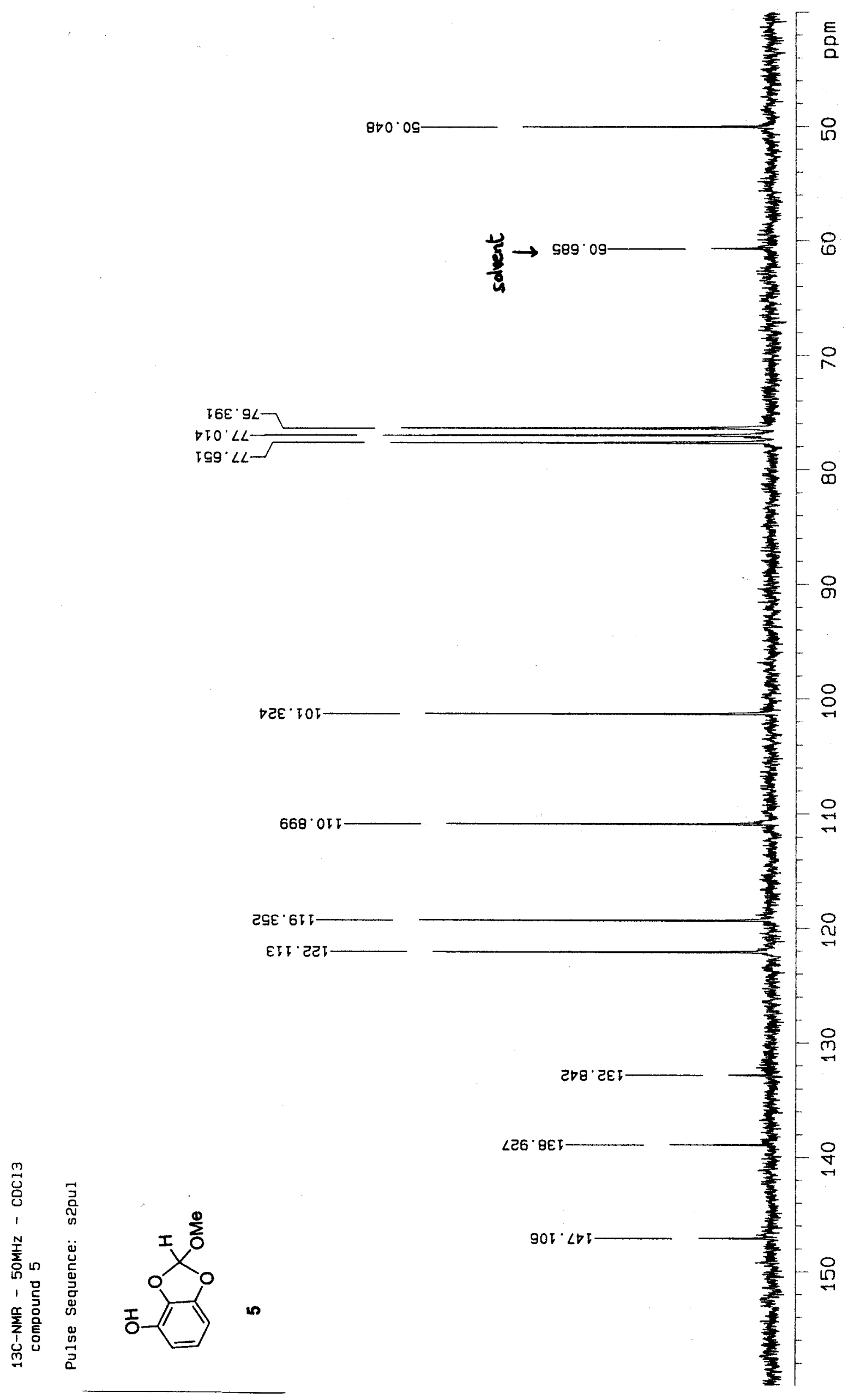



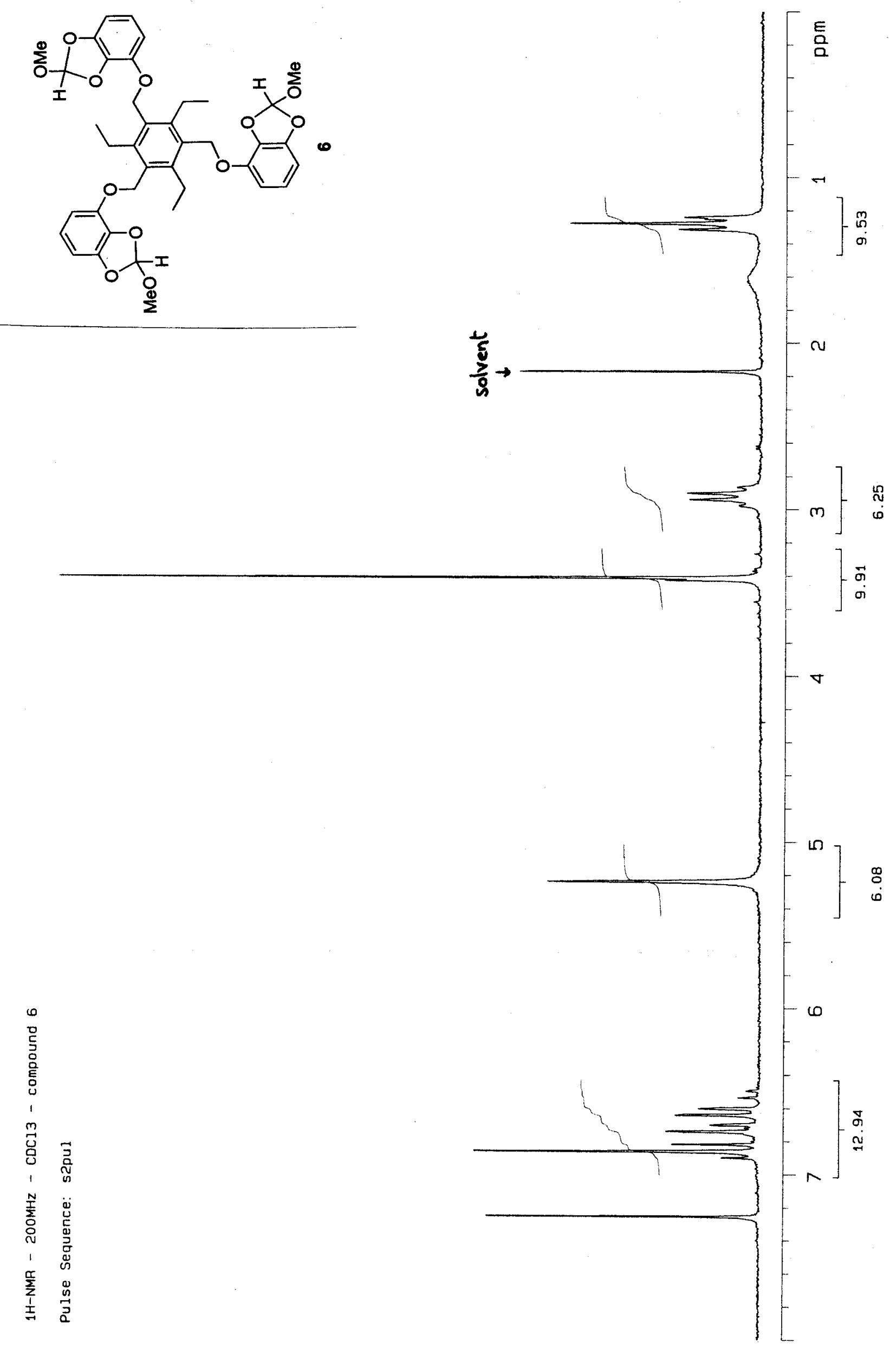


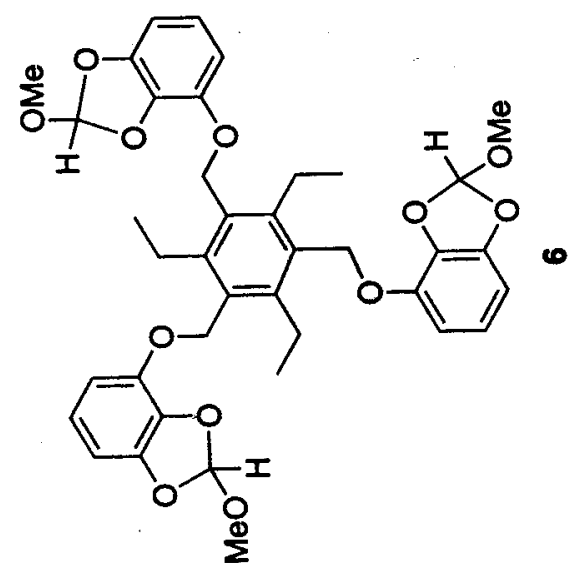

$\angle \mathrm{GG} \cdot 9$

อนเEZ-

$2 \nabla 6.6$

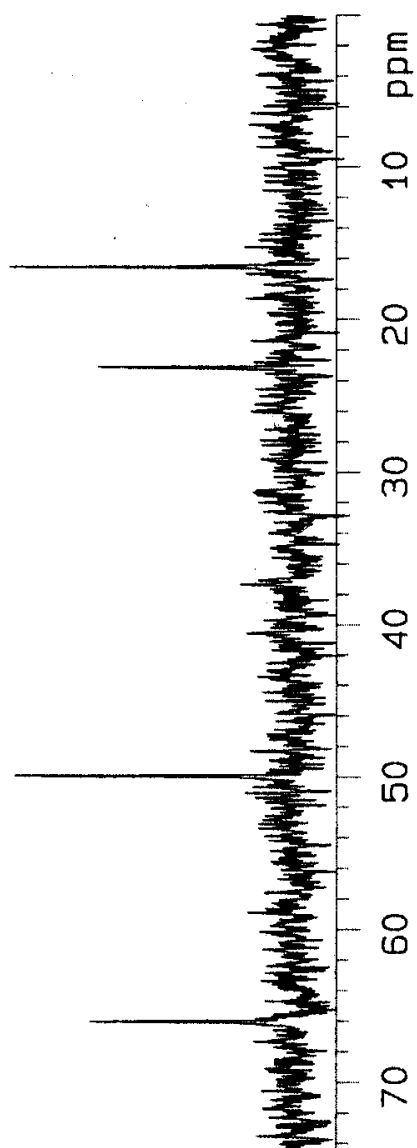

I $9 \varepsilon^{\prime} 9 L$

$866^{\circ} 9$

9E9 $\angle L$

$\angle 90 \cdot 99$

$288^{\circ} 60 \mathrm{~T}$

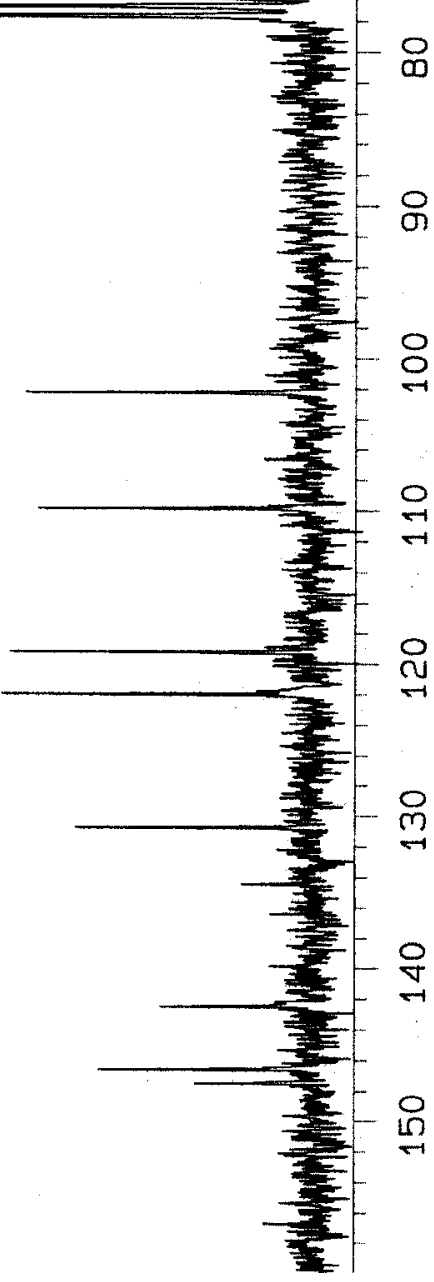

OE2 $6 I$

ट66 ' 2
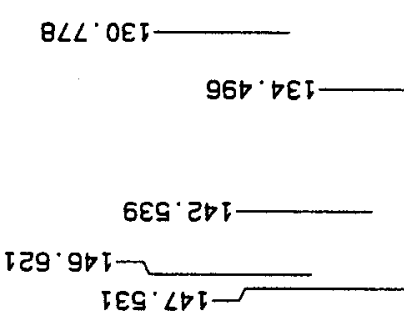


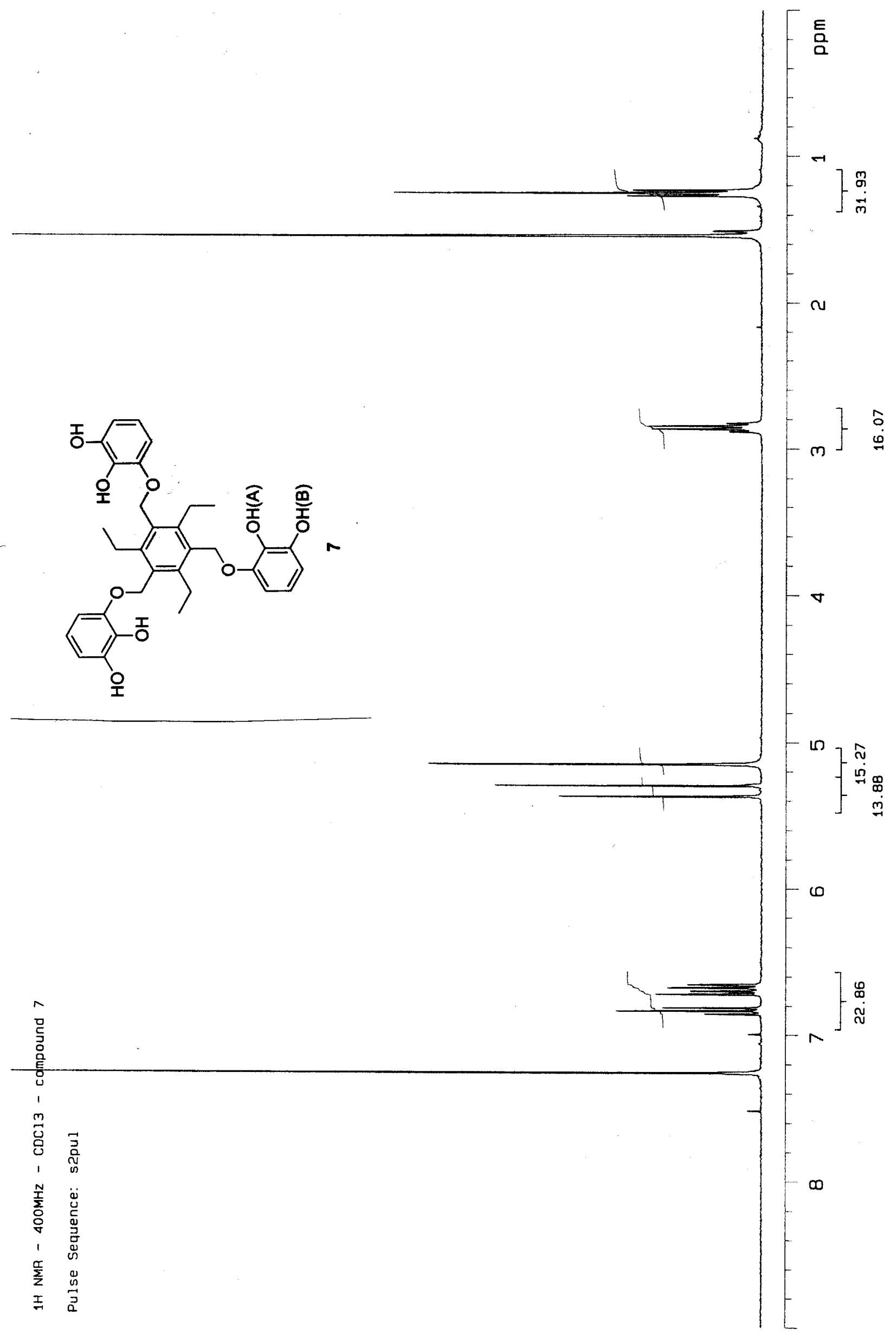



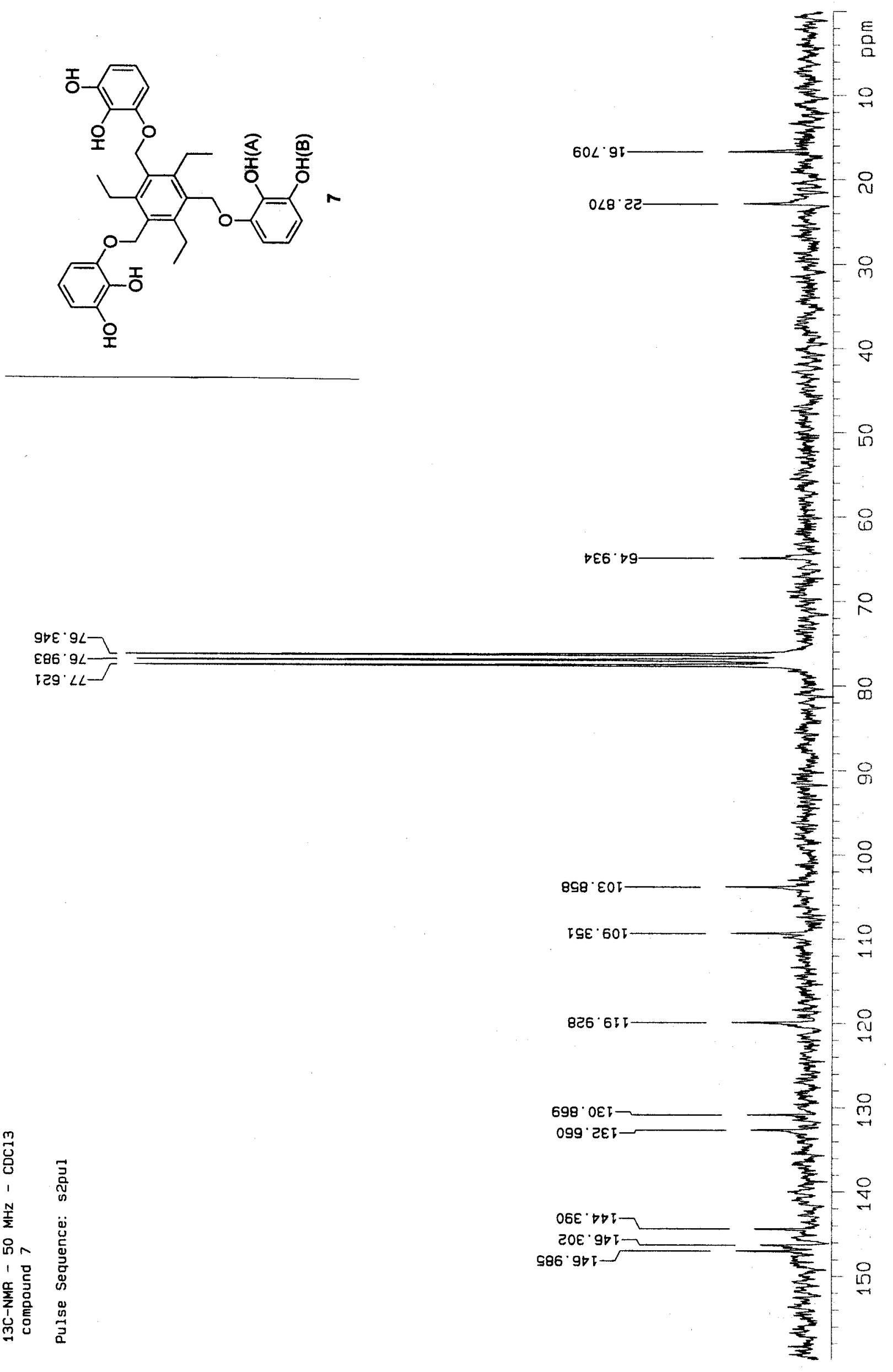


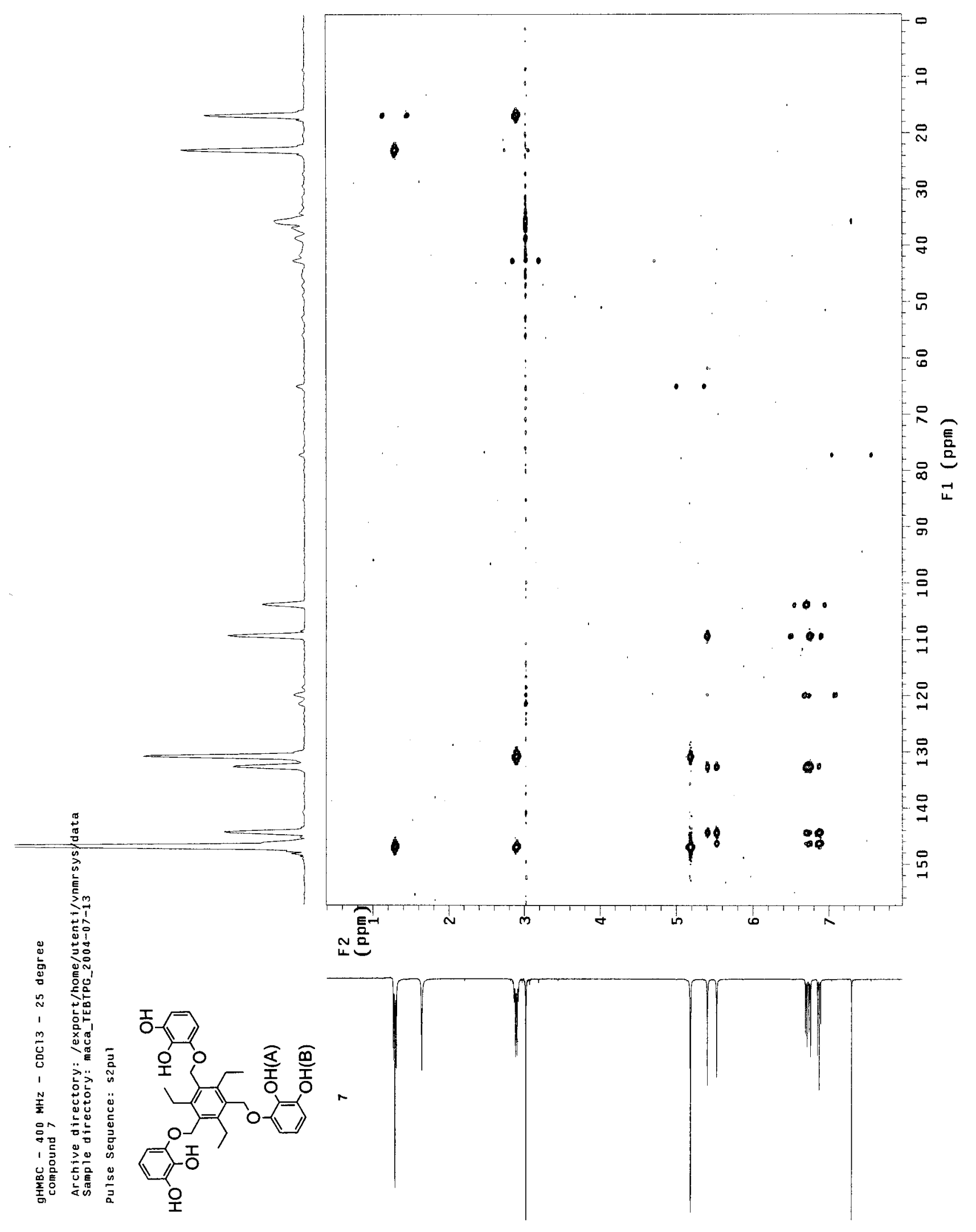




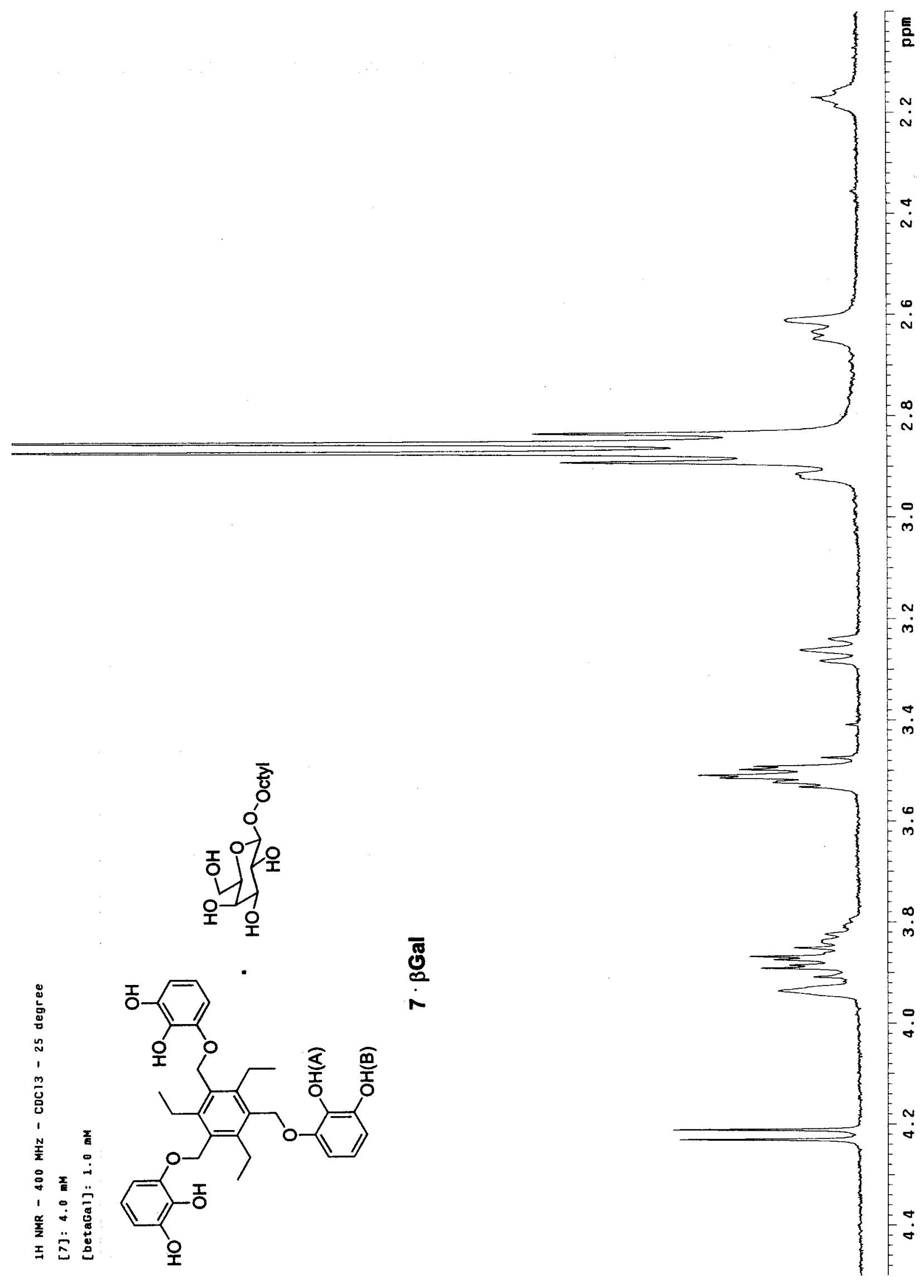




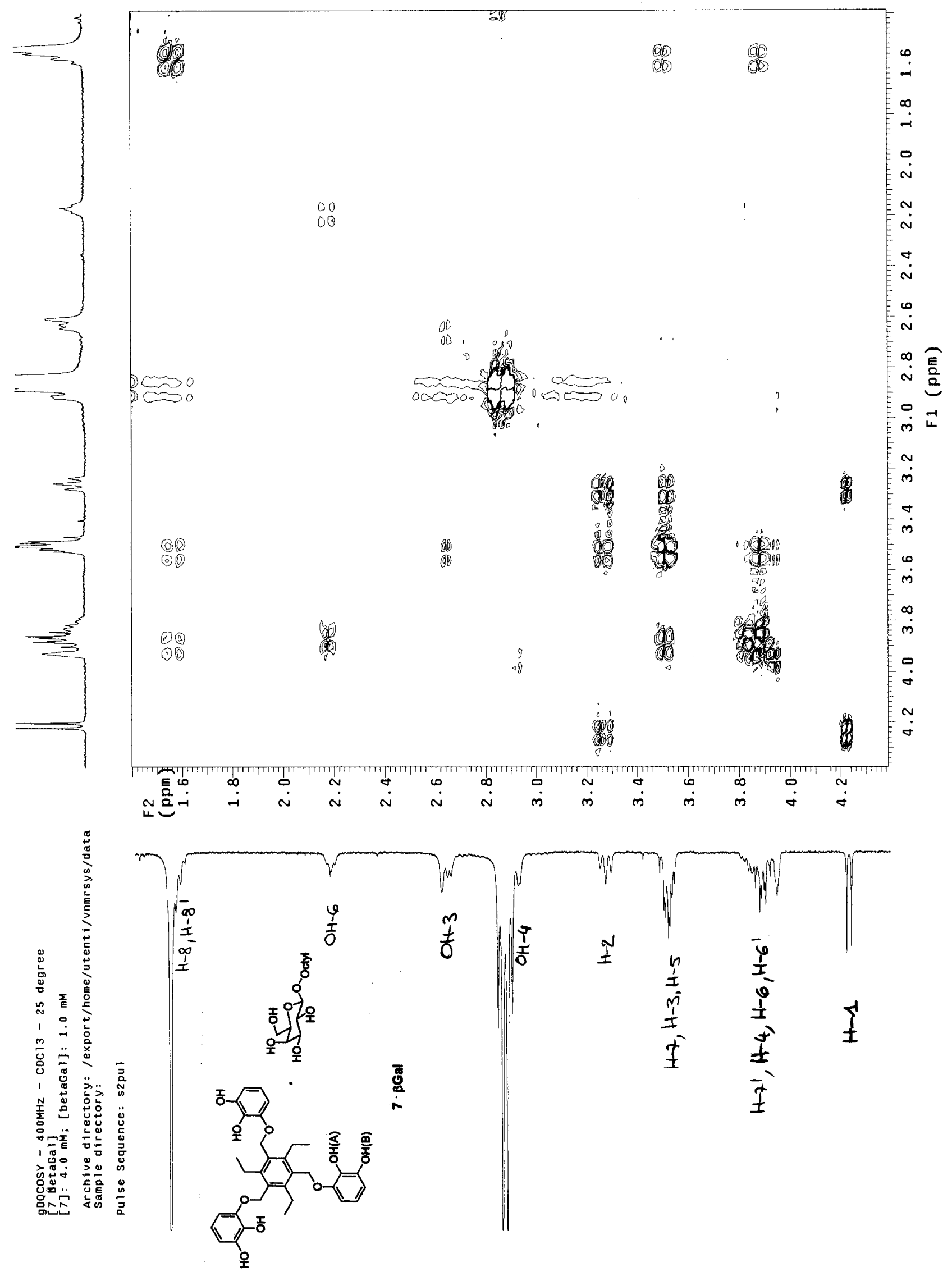

